\title{
Resistência a antimicrobianos dependente do sistema de efluxo multidrogas em Escherichia coli isoladas de leite mastítico
}

[Antimicrobial resistance dependent on multidrugs efflux in Escherichia coli isolated from the mastitic milk]

\author{
M.A.S. Moreira ${ }^{1}$, A.B. Ferreira ${ }^{2}$, T.F.S.L. Trindade ${ }^{1}$, A.L.O. Reis ${ }^{1}$, C.A. Moraes $^{2}$ \\ ${ }^{1}$ Departamento de Veterinária - UFV \\ Av. P.H. Rolfs, s/n \\ 36570-000 - Viçosa, MG \\ ${ }^{2}$ Instituto de Biotecnologia Aplicada à Agropecuária - UFV - Viçosa, MG
}

\begin{abstract}
RESUMO
Identificaram-se e caracterizaram-se a resistência e a multirresistência aos principais antimicrobianos usados no tratamento de mastite bovina causada por Escherichia coli. A concentração inibitória mínima (MIC) e o sistema de efluxo foram detectados pelas curvas de crescimento, com base na densidade óptica, em diferentes concentrações da droga e na presença e na ausência do desacoplador da força prótonmotora (PMF). E. coli 1 foi resistente à neomicina e à gentamicina; E. coli 3 e 4 , à tetraciclina e à estreptomicina; e E. coli 2 e 6 à gentamicina. E. coli 5 apresentou modelo de sensibilidade. Observou-se que MICs de todos os antimicrobianos dos multirresistentes (E. coli 1,3 e 4$)$ diminuíram na presença do desacoplador, o que sugere sistema de efluxo multidrogas. Após cura, apenas E. coli 1 apresentou modelo de sensibilidade, porém não houve alterações das MICs, antes e após adição do desacoplador. Os resultados indicam possível presença de mecanismo de resistência dependente da PMF codificado, ou parte dele, em plasmídeo.
\end{abstract}

Palavras-chave: Escherichia coli, sistema de efluxo, multirresistência, mastite, antimicrobiano

\begin{abstract}
Resistance and multiresistance to main antimicrobials used for treating bovine mastitis caused by Escherichia coli were identified and characterized. The minimal inhibitory concentration (MIC) and efflux systems were detected by the use of growth curves based on optical density at different drug concentrations and both presence and absence of uncoupler of the proton-motive force (PMF). E. coli 1 was resistant to neomycin and gentamycin, E. coli 3 and 4 were resistant to tetracycline and streptomycin, whereas E. coli 2 and 6 were resistant to gentamycin. E. coli 5 showed sensibility model. MICs of all antimicrobials of the multiresistant samples (E. coli 1, 3, and 4) were decreased in presence of the uncoupler, therefore suggesting the presence of the multidrug efflux system. After healing, only E. coli 1 showed sensibility model, however no alteration occurred in MIC(s) before and after adding the uncoupler. Those data inform the possible presence of a PMF dependent resistance mechanism that is totally or partly codified in plasmid.
\end{abstract}

Keywords: Escherichia coli, efflux system, multirresistance, mastitis, antimicrobial

\section{INTRODUÇ̃̃O}

A mastite é uma doença importante, complexa e dispendiosa para a indústria leiteira, visto que é constituída de infecções clínicas e subclínicas (Melchior et al., 2005). Seu efeito é notado pela redução da produção e pelas alterações na composição do leite, além de risco potencial à saúde pública, já que promove a veiculação de patógenos causadores de zoonoses e toxinas produzidas por estes (Wells et al., 1998; Reed e Grivetti, 2000; Nader Filho et al., 2007).

Recebido em 4 de janeiro de 2008 
Tem-se observado aumento considerável no número de bactérias resistentes aos antimicrobianos, inclusive resistentes a mais de um, simultaneamente (Piddock, 2006). Os mecanismos de resistência são complexos e numerosos (Aminov et al., 2001). As bactérias podem tornar-se resistentes por meio de mutações ou transferências horizontais de genes, que codificam bombas de efluxo, enzimas degradativas e modificadoras, e proteínas de proteção ribossomal (Khachatryan et al., 2004).

Os genes envolvidos na resistência aos antimicrobianos localizam-se no cromossomo e em elementos móveis, como plasmídeos e transposons (Aminov et al., 2001). A localização desses genes em elementos móveis facilita sua transferência entre as bactérias, mesmo de espécies diferentes (Miller, 1998; Ochaman et al., 2000). Um mecanismo de resistência denominado sistema de efluxo multidrogas (MDR) é preocupante, visto que a aquisição de um único sistema por uma célula pode diminuir a susceptibilidade dessa a amplo espectro de quimioterápicos (Paulsen et al., 1996; Piddock, 2006). As proteínas transportadoras que compõem esses sistemas estão ligadas também a transportes de nutrientes importantes para a célula (Saier et al., 1998). Nos procariotos, a maioria dos sistemas de efluxo é realizada pelo transporte ativo secundário, com gasto de energia oriunda da força próton-motora, que funciona como transporte antiporte droga/próton (Van Veen e Konings, 1997).

Os microrganismos causadores de mastites foram agrupados de acordo com as fontes de infecção e as vias de transmissão, e classificados como contagiosos ou ambientais (Radostits et al., 2002). E. coli é considerada um dos principais agentes da mastite bovina de origem ambiental (Kaipainem et al., 2002; Bean et al., 2004; Ribeiro et al., 2006). As infecções por $E$. coli na glândula mamária estão relacionadas com o comportamento oportunista do agente, que é veiculado pelas fezes dos animais e utiliza a via ascendente do canal galactóforo (Eberhart, 1979). Sabe-se que E. coli faz parte da microbiota intestinal dos animais, inclusive do homem, e que os ambientes humanos e animais não são separados, razão pela qual as bactérias de origem animal podem passar para os seres humanos (Van Den Bogaard e Stobberingh, 2000). Além disso, os determinantes de resistência às drogas de diferentes fontes podem ser transferidos entre as bactérias. (Van Den Bogaard e Stobberingh, 2000).

Objetivou-se caracterizar a resistência e a multirresistência em $E$. coli, isoladas de leite mastítico, aos antimicrobianos utilizados no tratamento de mastite bovina e detectar a presença de mecanismo de resistência dependente da força próton-motora, como sistema de efluxo multidroga.

\section{MATERIAL E METODOS}

Para a amostragem do leite, foi utilizada amostra não probabilística do tipo conveniência, para se obterem isolados de E. coli de leite mastítico. Foram coletadas 173 amostras de leite mastitico, em uma propriedade localizada na bacia leiteira da microrregião de Viçosa, $\mathrm{MG}$, que, na época das coletas, possuía, em média, 56 animais em lactação. A escolha pela propriedade se deu pelo fato de a mesma fazer parte do projeto de extensão universitária de assessoria a produtores de leite, desenvolvido por integrantes da equipe deste trabalho, facilitando-se, assim, a coleta das amostras. Foram realizadas oito coletas de amostras durante quatro meses, de abril a julho de 2005. O leite mastítico foi obtido de forma asséptica, aproximadamente $10 \mathrm{ml}$, dos quartos mamários comprometidos, de modo que, para cada animal, houvesse somente uma amostra por coleta. Para auxiliar no diagnóstico da mastite, foram usados a caneca de fundo escuro, o California Mastitis Test e o exame físico do úbere.

As amostras obtidas antes do tratamento com antimicrobianos foram transportadas em caixas isotérmicas ao Laboratório de Doenças Bacterianas do Departamento de Veterinária UFV e processadas imediatamente. $\mathrm{O}$ isolamento e a identificação foram realizados segundo Krieg e Hold, (1994) e Quinn et al. (1994). As amostras foram inoculadas em ágar sangue (5\% sangue de carneiro) e ágar MacConkey ${ }^{1}$, e incubadas a $37^{\circ} \mathrm{C}$ por 18 horas. Realizaram-se a coloração de Gram e os testes de produção de indol, vermelho de metila, Voges-Proskauer, citrato (IMViC) ${ }^{1}$ e oxidase por tiras ${ }^{2}$. Os isolados suspeitos foram inoculados em ágar Triple Sugar Iron ${ }^{1}$ (TSI) e

${ }^{1}$ Difco - Interlab - São Paulo, Brasil.

${ }^{2}$ Newpro - Pinhais, Brasil. 
em ágar Eosin Methylene Blue ${ }^{1}$ (EMB). A sorotipagem dos isolados de $E$. coli foi realizada no Instituto Adolfo Lutz, São Paulo.

O antibiograma foi feito pela metodologia de difusão de disco (Bauer et al., 1965). Os discos ${ }^{3}$ dos antimicrobianos usados foram sulfazotrim, enrofloxacin, tetraciclina, neomicina, estreptomicina e gentamicina. Os isolados foram reativados em caldo cérebro e coração ${ }^{4}$ (BHI), incubados a $37^{\circ} \mathrm{C}$, durante $16-18$ horas. As culturas foram diluídas em caldo $\mathrm{BHI}$, para $10^{5}$ UFC ml${ }^{-1}$, plaqueadas em ágar Mueller Hinton ${ }^{1} \mathrm{e}$ incubadas a $37^{\circ} \mathrm{C}$ por 18 horas. Os diâmetros dos halos de inibição foram medidos, calculando-se a média das duplicatas, e o resultado comparado com o padrão do $\mathrm{CLSI}^{5}$.

A determinação da concentração inibitória mínima (MIC) e do sistema de efluxo dependente da força próton-motora (PMF) baseou-se em Moreira et al. (2005): 230 $\mu$ de cada cultura, reativada em caldo BHI e diluída em caldo BHI para $10^{5}$ UFC $\mathrm{ml}^{-1}$, foram adicionados à placa de microtitulação ${ }^{6}$, juntamente com os antimicrobianos, nas diferentes concentrações, em um total de $300 \mu \mathrm{l}$ por orifício. O crescimento dos isolados foi acompanhado em aparelho leitor de ELISA $^{7}$, e as leituras foram feitas em intervalos preestabelecidos. A curva de crescimento foi construída com a média aritmética das triplicatas. A MIC foi estabelecida como a menor concentração do antimicrobiano que impedia o crescimento bacteriano até duas horas após o tempo correspondente ao início da fase estacionária do controle (cada isolado cultivado em BHI sem antimicrobiano). Para detecção do sistema de efluxo dependente de energia, foi usado um desacoplador da PMF, motora, carbonil cianeto m-clorofenilhidrazona $(\mathrm{CCCP})^{8}$ que diminui a energia disponível ao transporte. Previamente, foram realizados testes com diversas concentrações de $\mathrm{CCCP}$, para cada isolado. A concentração de CCCP, escolhida para cada isolado, foi a maior que mantinha a curva padrão de crescimento bacteriano normal. O volume final, para cada orifício, foi de $300 \mu$,

\footnotetext{
${ }^{3}$ Laborclin - Pinhais, Brasil.

${ }^{4}$ Oxolid - Basingstone, Inglaterra.

${ }^{5}$ Clinical and Laboratory Standards Institute - Wayne, EUA.

${ }^{6}$ Nunc-Immuno ${ }^{\mathrm{TM}}$ plates - Dinamarca.

${ }^{7}$ Titertek multiskan $^{\circledR}$, Plus-MkII - Huntsville, EUA.

${ }^{8}$ Sigma - St. Louis, EUA.
}

sendo $230 \mu \mathrm{l}$ padronizados para a adição da cultura bacteriana $10^{5}$ UFC $\mathrm{ml}^{-1}$, e os $70 \mu \mathrm{l}$ restantes formados por antimicrobiano, CCCP e água ultrapura (Millipore). A redução da MIC, em presença do desacoplador, indica a necessidade da PMF para o mecanismo de resistência. Todos os procedimentos foram realizados, duas vezes, em triplicata, juntamente com os controles necessários.

Para avaliar a estabilidade do fenótipo do mecanismo de resistência, foi realizada a cura de plasmídeos. Das culturas de E. coli, $50 \mu$ foram repassados 15 vezes em $2 \mathrm{ml}$ de caldo BHI estéril, a cada $18-20$ horas, a $37^{\circ} \mathrm{C}$ (Trevors, 1986; Crosa et al., 1994), e, em seguida, novos antibiogramas foram realizados para avaliar alterações dos modelos de resistência dos subsolados. Em caso de mudança, do modelo de resistente para sensível, nova detecção da MIC foi realizada na presença e na ausência do CCCP, conforme descrito anteriormente.

\section{RESULTADOS E DISCUSSÃO}

Foram identificados seis isolados de $E$. coli provenientes de diferentes animais. Os isolados apresentaram colônias de aspecto seco e de coloração rósea em ágar MacConkey; positividade no teste da oxidase; e foram visualizados bastonetes curtos Gram-negativos. No teste IMViC, apresentaram resultados positivos para produção de indol e vermelho de metila, e negativos para Voges-Proskauer e citrato. Observaram-se no ágar TSI grande formação de gás e coloração amarela na superfície (Y) e no fundo (Y) do tubo, sem formação de $\mathrm{H}_{2} \mathrm{~S}\left(\mathrm{Y} / \mathrm{Y} / \mathrm{H}_{2} \mathrm{~S}-\right)$. No ágar BEM, observaram-se colônias verdes brilhantes. Pela chave de identificação fenotípica, os dados indicam E. coli. (Krieg e Holt, 1994). O isolado E. coli 5 foi sorotipado como Ont:H- (antígeno $\mathrm{O}$ não-tipado e antígeno $\mathrm{H}$ ausente), enquanto os demais foram Ont:Hnt (O e $\mathrm{H}$ : antígenos; nt: não-tipado).

Os antimicrobianos usados para realização dos antibiogramas foram alguns dos prescritos no tratamento da mastite causada por E. coli. A Tab. 1 mostra a caracterização da resistência e da multirresistência dos isolados.

Embora os isolados apresentassem sensibilidade a várias drogas usadas no tratamento da mastite 
(Tab. 1), nos resistentes (Tab. 1) o uso dessas drogas poderá resultar no insucesso do tratamento, como também poderá selecionar microrganismos ainda mais resistentes dentro de uma população. A pressão seletiva é exercida também na microbiota comensal normal, que forma um reservatório de genes de resistência (Aminov et al. 2001).
Apenas um isolado, E. coli 5, não foi resistente a nenhum dos antimicrobianos usados, enquanto os demais isolados apresentaram resistência a, pelo menos, um antimicrobiano (Tab. 1). Ribeiro et al. (2006) constataram que $20 \%$ dos isolados de E. coli obtidos de mastite bovina apresentaram resistência a dois ou mais antimicrobianos, entre estes, à gentamicina e à neomicina.

Tabela 1. Modelo de resistência das amostras de E. coli isoladas de leite mastítico

\begin{tabular}{lcccccc}
\hline \multirow{2}{*}{ Amostra } & \multicolumn{6}{c}{ Antimicrobiano } \\
\cline { 2 - 7 } & Sut & Eno & Tet & Neo & Est & Gen \\
\hline E. coli 1 & $\mathrm{~S}$ & $\mathrm{~S}$ & $\mathrm{~S}$ & $\mathrm{R}$ & $\mathrm{S}$ & $\mathrm{R}$ \\
E. coli 2 & $\mathrm{~S}$ & $\mathrm{~S}$ & $\mathrm{~S}$ & $\mathrm{~S}$ & $\mathrm{~S}$ & $\mathrm{R}$ \\
E. coli 3 & $\mathrm{~S}$ & $\mathrm{~S}$ & $\mathrm{R}$ & $\mathrm{S}$ & $\mathrm{R}$ & $\mathrm{S}$ \\
E. coli 4 & $\mathrm{~S}$ & $\mathrm{~S}$ & $\mathrm{R}$ & $\mathrm{S}$ & $\mathrm{R}$ & $\mathrm{S}$ \\
E. coli 5 & $\mathrm{~S}$ & $\mathrm{~S}$ & $\mathrm{~S}$ & $\mathrm{~S}$ & $\mathrm{~S}$ & $\mathrm{~S}$ \\
E. coli 6 & $\mathrm{~S}$ & $\mathrm{~S}$ & $\mathrm{~S}$ & $\mathrm{~S}$ & $\mathrm{~S}$ & $\mathrm{R}$ \\
\hline
\end{tabular}

Sut: sulfazotrim; Eno: enrofloxacina; Tet: tetraciclina; Neo: neomicina; Est: estreptomicina; Gen: gentamicina; S: sensível; R: resistente.

Para cada isolado, foi determinada a maior concentração de CCCP, que mantinha a curva de crescimento idêntica à curva padrão, isto é, a curva obtida da cultura sem adição do desacoplador. Para E. coli 1, a concentração máxima de CCCP foi $15 \mu \mathrm{M}$ e para os demais isolados, $20 \mu \mathrm{M}$. A Fig. 1 mostra o efeito das concentrações de CCCP sobre o crescimento de E. coli 1 . Foi necessário conhecer a concentração do desacoplador que não modificasse o crescimento celular, mas influenciasse, em nível mínimo, o gradiente de prótons da membrana plasmática. Sabe-se que as proteínas transportadoras que dependem do gradiente de prótons, além de estarem envolvidas em mecanismos de resistência a antimicrobianos, também estão ligadas a transportes importantes e naturais para a célula, como açúcares, aminoácidos, proteínas, complexos férricos, carboidratos e outros (Saier et al., 1998). A maioria dos sistemas de efluxo multidrogas conhecidos em bactérias é sensível a agentes que dissipam a força próton-motora, o que indica transporte ativo de compostos tóxicos para fora da célula acoplada à entrada de prótons (Bolhuis et al., 1994; Bolhuis et al., 1995; Putman et al., 2000).

As concentrações inibitórias mínimas, antes da adição do desacoplador, variaram de $5 \mu \mathrm{g} \mathrm{ml}^{-1}$ a
$30 \mu \mathrm{g} \mathrm{ml}^{-1} \mathrm{e}$, após a adição do CCCP, de $5 \mu \mathrm{g} \mathrm{ml}^{-1}$ a $10 \mu \mathrm{g} \mathrm{ml}^{-1}$. Na Tab. 2, encontram-se os valores das MICs dos antimicrobianos na presença e ausência do CCCP.

Observou-se diminuição das MICs, após adição de CCCP, dos antimicrobianos presentes nos modelos de resistência dos isolados E. coli $1, E$. coli 3 e E. coli 4 (Tab. 2), sugerindo que o mecanismo de resistência desses antimicrobianos seja dependente da energia oriunda da PMF. É interessante notar que, em cada um desses isolados, os dois antimicrobianos presentes nos seus modelos de resistência diminuíram na presença do desacoplador, o que indica possível presença de um sistema de efluxo multidrogas. Porém, sabe-se que o fenótipo de multirresistência nem sempre é devido a um único sistema de efluxo multidroga, mas a vários sistemas de efluxo droga específica, sob um sistema global de regulação (Paulsen et al., 1996). Moreira et al. (2004) verificaram presença de sistemas de efluxo dependente da PMF em isolados de E. coli e Enterobacter cloacae, obtidos de carcaças de aves clinicamente sadias. Vários sistemas de efluxo multidrogas têm sido identificados em E. coli (Moreira et al., 2004). 
Tabela 2. Concentrações inibitórias mínimas de antimicrobianos presentes nos modelos de resistência de isolados de E. coli, na presença e na ausência do desacoplador (CCCP) em caldo BHI

\begin{tabular}{llcc}
\hline Bactérias & Antimicrobianos & $\begin{array}{c}\text { MIC } \\
\text { Ausência de CCCP } \\
\left(\mu \mathrm{g} \mathrm{ml}^{-1}\right)\end{array}$ & $\begin{array}{c}\text { MIC } \\
\text { Presença de CCCP } \\
\left(\mu \mathrm{gl}^{-1}\right)\end{array}$ \\
\hline E. coli 1 & Neomicina & 30 & 10 \\
E. coli 2 & Gentamicina & 10 & 5 \\
E. coli 3 & Gentamicina & 5 & 5 \\
& Tetraciclina & 10 & 5 \\
E. coli 4 & Estreptomicina & 80 & 50 \\
& Tetraciclina & 30 & $\leq 10$ \\
E. coli 6 & Estreptomicina & 70 & 50 \\
\hline
\end{tabular}

MIC: Concentração Inibitória Mínima; CCCP: carbonil cianeto m-clorofenilhidrazona.

O mecanismo de resistência da gentamicina, presente nos modelos de resistência de E. coli 2 e $E$. coli 6, provavelmente independa da PMF, pois não houve alterações das respectivas MICs, antes e após adição do CCCP (Tab. 2), fato não observado para esse antimicrobiano presente no modelo de resistência da $E$. coli 1 (Tab. 2). Observaram-se comportamentos diferentes da gentamicina, na presença do desacoplador, nos diferentes isolados. Sabe-se que ocorre sinergismo entre os vários mecanismos de resistência (Poole, 2001). A gentamicina, juntamente com a neomocina e a estreptomicina, são aminoglicosídeos, e o mecanismo de resistência mais comum a este grupo se deve à modificação da estrutura da droga por enzimas bacterianas, o que resulta no bloqueio da entrada da droga (Kurylowicz, 1981). Na tetraciclina, os dois principais mecanismos de resistência são por efluxo dependente de energia e por proteção dos ribossomos pelas grandes proteínas citoplasmáticas (Speer et al., 1992; Aminov et al., 2001).

Pela metodologia usada, pode-se inferir que há mecanismos de resistência dependente da PMF nos isolados de $E$. coli 1,3 e 4, porém não se pode afirmar que o sistema de efluxo esteja ausente nos demais isolados. O sistema de efluxo poderia funcionar em nível indetectável, por essa metodologia adotada, e potencializar os outros mecanismos de resistência de maior expressão. Em bactérias, o sistema de efluxo pode diminuir a susceptibilidade aos antimicrobianos, entretanto, essa diminuição nem sempre resulta em resistência, em nível clínico (Piddock, 2006). O significado clínico desse sistema não é muito claro, mas, sem dúvida, está presente em bactérias, e o uso excessivo de uma droga exerceria pressão necessária para selecionar mutações que resultam em um sistema de efluxo eficiente. Mecanismos múltiplos de resistência a determinado antimicrobiano podem coexistir em um mesmo isolado bacteriano (Lee et al., 2000). Diferentes níveis de resistência, mostrados na Tab. 2, sugerem distintas combinações de estratégias de resistência.

As Fig. 2 e 3 mostram, respectivamente, a detecção da MIC da neomicina presente no modelo de resistência do isolado $E$. coli 1 , antes e após adição do desacoplador, CCCP.

Para verificar a possível localização dos genes de resistência, foi realizada a cura de plasmídeos dos isolados. A perda do fenótipo de resistência foi diretamente associada à perda de plasmídeos. Apenas no isolado E. coli 1 foi observado esse fenótipo, inicialmente resistente à neomicina e à gentamicina; após o procedimento de cura, foi sensível a ambas. Novas MICs nesses antimicrobianos foram detectadas, em meio líquido, na presença e na ausência de $15 \mu \mathrm{M}$ CCCP. O isolado E. coli 1, após o processo de cura, apresentou sensibilidade a $10 \mu \mathrm{g}$ de gentamicina e a $30 \mu \mathrm{g}$ de neomicina, em meio sólido, porém não houve alterações das MICs, antes e após adição do CCCP. Os valores das MICs, em meio líquido, de neomicina e gentamicina foram, respectivamente, $2,5 \mu \mathrm{g} \mathrm{ml} \mathrm{m}^{-1} \mathrm{e} 30 \mu \mathrm{g} \mathrm{m} \mathrm{m}^{-1}$. Estes dados sugerem a presença de mecanismo de resistência à gentamicina e à neomicina total ou parcialmente codificado em plasmídeo e dependente de energia oriunda da força próton motora, uma vez que o isolado $E$. coli 1 selvagem mostrou MICs diferentes, na presença e na ausência de CCCP. Este isolado é um candidato, em potencial, para estudos moleculares de sistemas de efluxo multidrogas. 


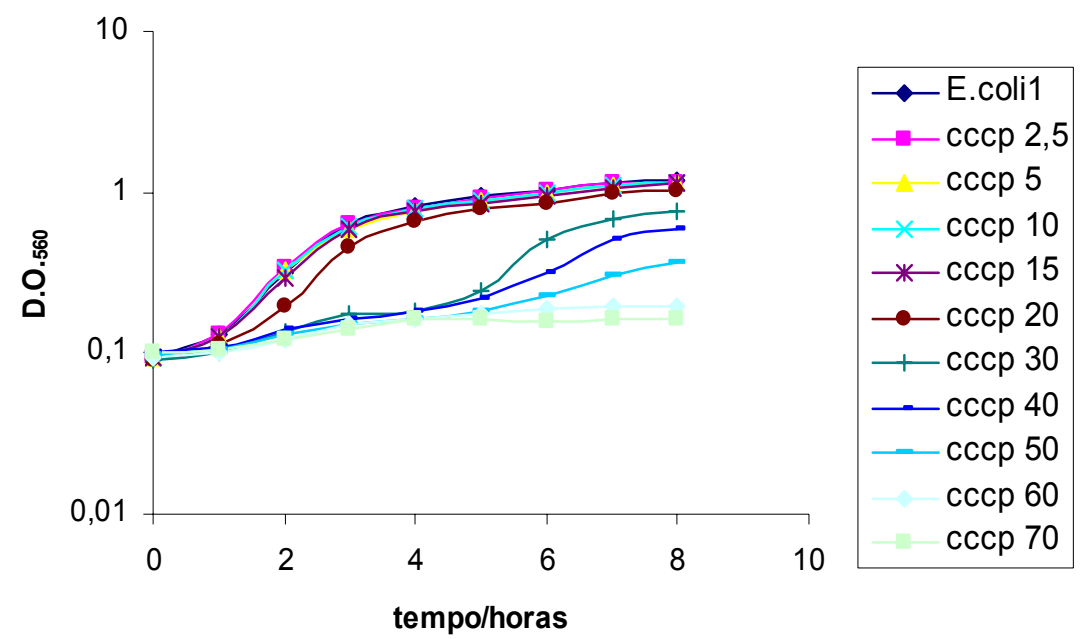

Figura 1. Efeito de concentrações $(\mu \mathrm{M})$ carbonil cianeto m-clorofenil hidrazona, CCCP, sobre o crescimento de E. coli 1 em caldo BHI.

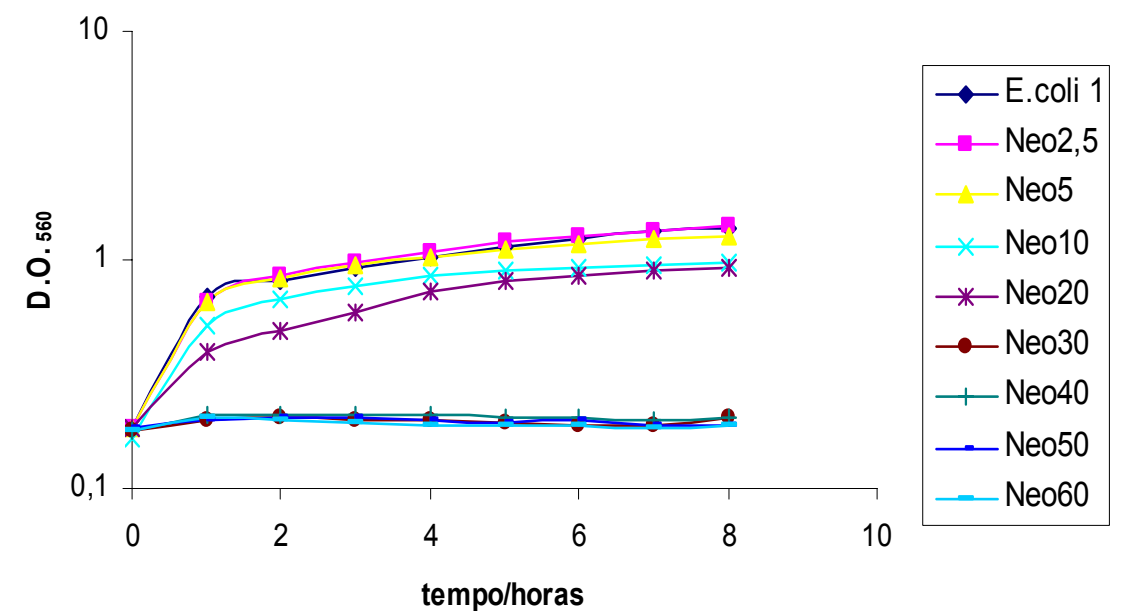

Figura 2. Efeito de concentrações $\left(\mu \mathrm{g} \mathrm{ml}^{-1}\right)$ de neomicina (Neo) sobre o crescimento de $E$. coli 1 em caldo BHI.

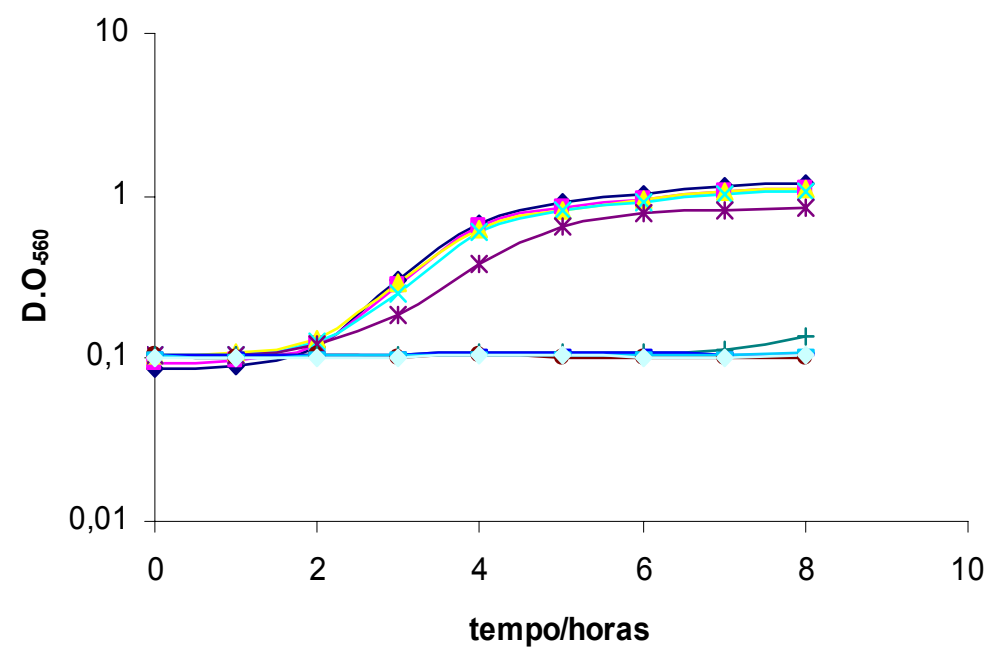

Figura 3. Efeito da concentração de $15 \mu \mathrm{M}$ de carbonil cianeto m-clorofenil hidrazona sobre o crescimento de E. coli 1 em caldo BHI, com diferentes concentrações $\left(\mu \mathrm{g} \mathrm{ml}^{-1}\right)$ de neomicina (neo). 


\section{CONCLUSÃO}

Cinco isolados de E. coli, obtidos de leite mastítico, apresentaram modelos de resistência e de multirresistência aos antimicrobianos usados no tratamento da mastite ambiental, com presença de mecanismo de resistência dependente da força próton-motora total ou parcialmente codificado em plasmídeo.

\section{AGRADECIMENTOS}

À Fundação de Amparo à Pesquisa do Estado de Minas Gerais - FAPEMIG, pelo financiamento da pesquisa.

\section{REFERÊNCIAS BIBLIOGRÁFICAS}

AMINOV, R.I.; GARRIGUES-JEANJEAN, N.; MACKIE, R.I. Molecular ecology of tetracycline resistance: development and validation o primers for detection of tetracycline resistance genes encoding ribossomal protection proteins. Appl. Environ. Microbiol., v.67, p.22-32, 2001.

BAUER, A.W.; KIRBY, V.M.M.; SHERRIS, J.C. et al. Antibiotics susceptibility testing by a stantardized single disk method. Am. J. Clin. Pathol., v.45, p.493-496, 1965.

BEAN, A.; WILLIAMSON, J.; CURSONS, R.T. Virulence genes of Escherichia coli strains isolated from mastitic milk. J. Vet. Med. B., v.5, p.285-287, 2004.

BOLHUIS, H.; MOLENAAR, D.; POELARENDS, G. et al. Proton motive forcedriven and ATP-dependent drug extrusion systems in multidrug-resistant Lactococcus lactis. J. Bacteriol., v.176, p.6957-6964, 1994.

BOLHOUIS, H.; POELARENDS, G.; VAN VEEN, H.W. et al. The lactococcal lmrl gene encodes a proton motive force-dependent drug transporter. J. Biol. Chem., v.270, p.2609226098, 1995.

CROSA, J.H.; TOLMASKY, M.E.; ACTIS, L.A. et al. Plasmids. In: MURRAY, R.G.E.; WOOD, W.A.; KRIEG, N.R. (Eds). Methods for general and molecular bacterioloy. Washington, D.C: American Society for Microbiology, 1994. p.365-386.

EBERHART, R.J. Coliform mastitis - a review. J. Dairy Sci., v.62, p.1-22, 1979.
KAIPAINEN, T.; POHJANVIRTA, T.; SHPIGEL, N.Y. et al. Virulence factors of Escherichia coli isolated from bovine clinical mastitis. Vet. Microbiol., v.85, p.37-46, 2002.

KHACHATRYAN，A.R.; HANCOCK，D.D.; BESSER, T.E. et al. Role of calf-adapted Escherichia coli in maintenance of antimicrobial drug resistance in dairy calves. Appl. Environ. Microbiol., v.70, p.752-757, 2004.

KRIEG, N.R.; HOLT, J.C (Eds). Bergey's manual of systematic bacteriology. 9.ed. Baltimore: Williams Wilkins, 1994. 984p.

KURYLOWICZ, W. (Ed). Antibióticos - uma revisão critica. 1.ed. Recife: UFPE, 1981. 341p.

LEE, A.; MAO, W.; WARREN, M.S. et al. Interplay between efflux pumps may provide either additive or multiplicative effects on drug resistance. J. Bacteriol., v.182, p.3142-3150, 2000.

MELCHIOR, M.B.; VAARKAMP, H.; FRINKGREMMELS, J. Biofilms: a role in recurrent mastitis infections? Vet. J., v.171, p.398-407, 2005.

MILLER, R.V. Bacterial gene swapping in nature. Sci. Am., v.278, p.66-71, 1998.

MOREIRA, M.A.S.; OLIVEIRA' J.A.; TEIXEIRA, L.M. et al. Chloramphenicol efflux system in Escherichia coli isolated from poultry carcasse. Vet. Microbiol., v.109, p.75-81, 2005.

MOREIRA, M.A.S.; SOUZA, E. C.; MORAES, C.A. Multidrug efflux systems in Gram-negative bacteria. Braz. J. Microbiol., v.35, p.19-28, 2004.

NADER FILHO, A.; FERREIRA, L.M.; AMARAL, L.A. et al.Produção de enterotoxinas e da toxina da síndrome do choque tóxico por cepas de Staphylococcus aureus isoladas na mastite bovina. Arq. Bras. Med. Vet. Zootec., v.59, p.1316-1318, 2007.

OCHMAN, H.; LAWRENCE, G.; GROISMAN, E.A. Lateral gene transfer and the nature of bacterial innovation. Nature, v.405, p.299-304, 2000 .

PAULSEN, I.T.; BROWN, M.H.; SKURRAY, R.A. Proton-dependent multidrug efflux systems. Microbiol. Rev., v.60, p.575-608, 1996. 
PIDDOCK, L.J.V. Multidrug-resistance efflux pumps-not just resistance. Nat. Rev. Microbiol., v.4, p.629-635, 2006.

POOLE, K. Multidrug resistance in Gramnegative bacteria. Curr. Opin. Microbiol., v.4, p.500-508, 2001.

PUTMAN, P.; VAN VEEN, H.; KONINGS, N. Molecular properties of bacterial multidrug transporters. Microbiol. Mol. Biol. Rev., v.64, p.672-693, 2000.

QUINN, P.J.; CARTER, M.E.; MARKEY, B. et al. Clinical Veterinary Microbiology. London: Mosby book, 1994. 648p.

RADOSTITS, O.M.; GAY, C.C.; BLOOD, D.C. et al. Clinica Veterinária, um tratado de doenças dos bovinos, ovinos, suinos, caprinos e eqüinos. 9.ed. Rio de Janeiro: Guanabara Koogan, 2002. $1770 \mathrm{p}$.

REED, B.A.; GRIVETTI, L.E. Controlling onfarm inventories of bulk-tank raw milk - an opportunity to protect public health. J. Dairy Sci., v.83, p.2988-2991, 2000.

RIBEIRO, M.G.; COSTA, E.O.; LEITE, D.S. et al. Fatores de virulência em linhagens de
Escherichia coli isoladas de mastite bovina. Arq. Bras. Med. Vet. Zootec., v.48, p.724-731, 2006.

SAIER JR., M.H.; PAULSEN, L.T.; SIIWINSKI, M.K. et al. Evolutionary origins of multidrug and drug specific efflux pumps in bacteria. FASEB J., v.12, p.265-274, 1998.

SPEER, B.S.; SHOEMAKER, N.B.; SALYERS, A.A. Bacterial resistance to tetracycline: mechanisms, transfer, and clinical significance. Clin. Microbiol Rev., v.5, p.387-399, 1992.

TREVORS, J.T. Plasmid curing in bacteria. FEMS Microbiol. Rev., v.321, p.149-157, 1986.

VAN DEN BOGAARD, A.E.; STOBBERINGH, E.E. Epidemiology of resistance to antibiotics links between animals and humans. Int. J. Antimicrob. Agents., v.14, p.327-335, 2000.

VAN VEEN, H.W.; KONINGS, W.N. Drug efflux proteins in multidrug resistant bacteria. $J$. Biol. Chem., v.378, p.769-777, 1997.

WELLS, S.J.; OTT, S.L.; HILLBERG SEITZINGER. A. Key health issues for dairy cattle - new and old. J. Dairy Sci., v.81, p.3029$3035,1998$. 